\title{
LGR5 expression is controled by IKKa in basal cell carcinoma through activating STAT3 signaling pathway
}

\author{
Jiantao Jia ${ }^{1,2,3, *}$, Ying Shi2,4,5,*, Bin Yan ${ }^{2,4,5, *}$, Deshen Xiao ${ }^{6}$, Weiwei Lai $2,4,5$, Yu Pan ${ }^{6}$, \\ Yiqun Jiang $2,4,5$, Ling Chen ${ }^{2,4,5}$, Chao Mao $^{2,4,5}$, Jian Zhou ${ }^{7,8}$, Sichuan Xi', Ya Cao ${ }^{2,4,5}$, \\ Shuang Liu ${ }^{1}$ and Yongguang Tao ${ }^{1,2,4,5}$ \\ ${ }^{1}$ Center for Medicine Research, Xiangya Hospital, Central South University, Changsha, Hunan, China \\ ${ }^{2}$ Cancer Research Institute, Central South University, Changsha, Hunan, China \\ ${ }^{3}$ Pathophysiology Department of Changzhi Medical College, Changzhi, Shanxi, China \\ ${ }^{4}$ Key Laboratory of Carcinogenesis and Cancer Invasion, Ministry of Education, Hunan, China \\ ${ }^{5}$ Key Laboratory of Carcinogenesis, Ministry of Health, Hunan, China \\ ${ }^{6}$ Department of Pathology, Xiangya Hospital, Central South University, Changsha, Hunan, China \\ ${ }^{7}$ Liver Surgery Department, Liver Cancer Institute, Zhongshan Hospital, Key Laboratory of Carcinogenesis and Cancer \\ Invasion (Fudan University), Ministry of Education, Fudan University, Shanghai, China \\ 8 Institute of Biomedical Sciences, Fudan University, Shanghai, China \\ ${ }^{9}$ Thoracic Surgery Section, Thoracic and GI Oncology Branch, Center for Cancer Research, National Cancer Institute, \\ Bethesda, MD, USA \\ * These authors have contributted equally to this work \\ Correspondence to: Shuang Liu, email: liushuang1999@yahoo.com \\ Yongguang Tao, email: taoyong@csu.edu.cn
}

Keywords: LGR5, IKKa, STAT3, BCC, EGF

Received: July 01, $2015 \quad$ Accepted: March 16, $2016 \quad$ Published: March 30, 2016

\section{ABSTRACT}

Basal cell carcinomas (BCC) of the skin are the most common of human cancers. The noncanonical NF-KB pathway is dependent on IKKa. However, the role of IKKa in $B C C$ has not been elucidated. We show here that IKKa is expressed in the nucleus in BCC and non-malignant diseases. Nuclear IKKa could directly bind to the promoters of inflammation factors and LGR5, a stem cell marker, in turn, upregulating LGR5 expression through activation of STAT3 signaling pathway during cancer progression. Activation of STAT3 signaling pathway contributes LGR5 expression in dependent of IKKa after the interplay between STAT3 and IKKa. Meanwhile knockdown of IKKa inhibits tumor growth and transition of epithelial stage to mescheme stage. Taken together, we demonstrate that IKKa functions as a bone fide chromatin regulator in BCC, whose promoted expression contributes to oncogenic transformation via promoting expression stemness- and inflammatory- related genes. Our finding reveals a novel viewpoint for how IKKa may involve in BCCs tumor progression in the inflammatory microenvironment.

\section{INTRODUCTION}

G-Protein-coupled receptor GPR49, also known as LGR5, belongs to the leucine-rich repeat containing G-protein-coupled receptors (LGRs) structurally similar to glycoprotein hormone receptors including thyroidstimulating hormone receptor, follicle-stimulating hormone receptor, and luteinizing hormone receptor, and functions as a marker of the crypt basal columnar stem cells along the gastrointestinal tract and of the bulge stem cells in the hair follicle [1, 2]. LGR5 is overexpressed in several types of cancer and can promote the growth/ metastasis of colon tumor cells [3].

Nuclear factor (NF)- $\mathrm{B}$ activation leads to a protumorigenic inflammatory microenvironment of various tumors [4]. The NF- $\kappa \mathrm{B}$ pathway is tightly

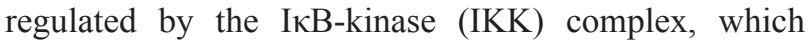
consists of two catalytic subunits, IKK $\alpha$ and IKK $\beta$, 
and a regulatory subunit, IKK $\gamma$ [5]. Whereas, in most malignancies, the classical IKK $\beta /$ IKK $\gamma$-dependent $\mathrm{NF}-\kappa \mathrm{B}$ activation controls key functions for tumor initiation, promotion and progression in tumors [6]. The noncanonical NF- $\kappa$ B pathway is dependent on IKK $\alpha$, and the role of IKK $\alpha$ in noncanonical NF- $\kappa B$ pathway is more complex [7, 8]. Depending on the type of malignancy, IKK $\alpha$ can provide both tumor-promoting and tumorsuppressive mechanisms that are in most instances cell autonomous.

Signal transducer and activator of transcription 3 (STAT3) mediates a key intrinsic pathway promoting tumorigenesis [9]. While constitutive STAT3 activity had initially been attributed to deregulated growth factor signaling, recent studies have identified STAT3 as an important mediator of carcinogenesis driven by chronic inflammation, obesity and/or metabolism, cancer stem cells (CSCs) [9-15]. STAT3 is constitutively active and associated with poor clinical prognosis in several cancers and consequently, STAT3 is an attractive target for pharmacologic intervention in cancer patients $[9,16]$.

Basal cell carcinoma (BCC) and squamous cell carcinoma (SCC) and are two major types of skin cancer derived from keratinocytes [17]. Although the mortality attributable to $\mathrm{BCC}$ is not high, the disease is responsible for considerable morbidity, imposing a growing burden on healthcare services $[18,19]$. In addition, IKK $\alpha$ reduction promotes chemical carcinogen- and ultraviolet B-induced skin carcinogenesis, and IKK $\alpha$ deletion in keratinocytes causes spontaneous skin SCCs, but not BCCs, in mice [2024]. However, the role of IKK $\alpha$ in BCCs remains poorly known.

Here we show that IKK $\alpha$ is expressed in BCCs while down-regulates in SCCs of skin cancer. The physiological role of IKK $\alpha$ in BCCs is related with LGR5 expression. Our findings further confirm that IKK $\alpha$ directly binds to the LGR5 promoter in dependent of activating STAT3 signaling pathway. Our finding reveals a novel viewpoint for how IKK $\alpha$ may involve in BCCs tumor progression in the inflammatory microenvironment.

\section{RESULTS}

\section{IKK $\alpha$ is dysregulated in skin-related tumors}

We first analyzed IKK $\alpha$ expression and subcellular localization by immunohistochemistry (IHC) in a panel section of 10 hemangioma, 54 SCC, 21 BCC and 13 metastasis cancer in skin and 70 sections of normal noncancerous tissues. The normal tissues were subdivided into 43 normal skins from various tissues, 9 papilloma, 8 nevus and 10 psoriasis (Figure 1A). IKK $\alpha$ were significantly down-expressed in SCCs and silenced in hemangioma, while IKK $\alpha$ level did not change in normal skin tissues, noncancerous tissues in papilloma, nevus and psoriasis. Unexpectedly, we also did not find the changes of IKK $\alpha$ in BCC and metastasis tissues (Figure 1A and Figure 1B).

Interestingly, although strong nuclear localization of IKK $\alpha$ was detected in normal stratified epithelia and BCC, the IKK $\alpha$ staining appeared stranded in the cytoplasm in SCC and metastasis skin tissues (Figure 1B). The ratio of cytoplasm to nuclear increased from 0.89 in normal skin, to 1.82 in SCC and to 5.85 in metastasis (Figure $1 \mathrm{C}$ ), indicating that down-regulation of IKK $\alpha$ in SCC and hemangioma and delocation of IKK $\alpha$ in SCC and metastasis may be associated with this critical step in tumor progression. It also hinted that nuclear IKK $\alpha$ might contribute to BCC carcinogenesis.

We noticed that about one fourth of SCCs did not detect IKK $\alpha$ expression, and we identified them as keratin SCC (Figure 1D). We further confirmed that keratin SCC was absence of IKK $\alpha$ as compared to BCC and normal skin (Figure 1E and 1F), indicating that the role of IKK $\alpha$ in skin cancer is dependent on the subtype of cancer.

\section{Inhibition of IKKa reduces LGR5 expression}

To address potential link of IKK $\alpha$ with LGR5, we first treated A431 cells, derived from a human epidermal carcinoma of the vulva, with IKK $\alpha$ inhibitor. We found that IKK inhibitor XII (IKK-i XII), an ATP site-targeting inhibitor against IKK [25], inhibited cell migration (Figure 2A). Using FACS, we found that IKK-i XII promotes G1 stage and decreased G2/M stages in A431 cells, indicating that inhibition of IKK in A431 cells might block cell cycle progression (Figure $2 \mathrm{~B}$ and $2 \mathrm{C}$ ).

After we treated A431 cells with IKK-i XII, we found that LGR5 level and phospharylated STAT3 (Y705) decreased while other proteins including LGR6, STAT3 and IKK $\alpha$ remained the same level (Figure 2D left). Similar findings were found in HaCaT cells, an immortalized human keratinocytes, after the treatment of IKK-i XII (Figure 2D right), indicating that IKK $\alpha$ might involve in the regulation of LGR5.

\section{Knockdown of IKKa decreases LGR5 expression}

To further identify link of IKK $\alpha$ with LGR5, we established an inducible knockdown of IKK $\alpha$ with RNAi that were selected from three shRNA sequences in both $\mathrm{HaCaT}$ and $\mathrm{A} 431$ cells. We first confirmed the inducible system knockdowned IKKa specially and efficiency (Supplementary Figure S1). After HaCaT cells were treated with different concentrations of doxycline (Dox) for $48 \mathrm{~h}$, we found that the inducible knockdown system successfully reduced IKK $\alpha$ protein to less than 10\% (Figure 3A). Meanwhile, LGR5 protein level also significantly decreased as company with knockdown of 
A

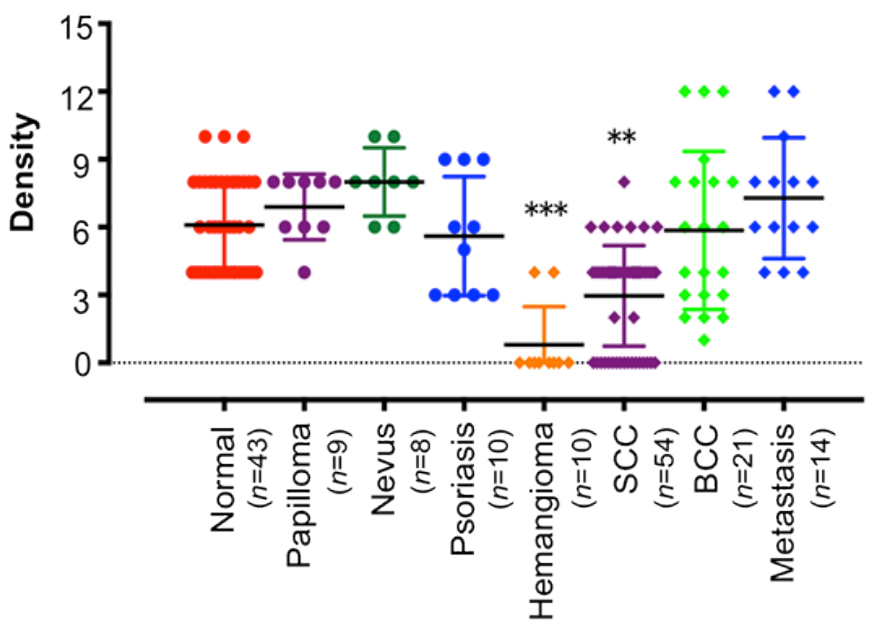

B

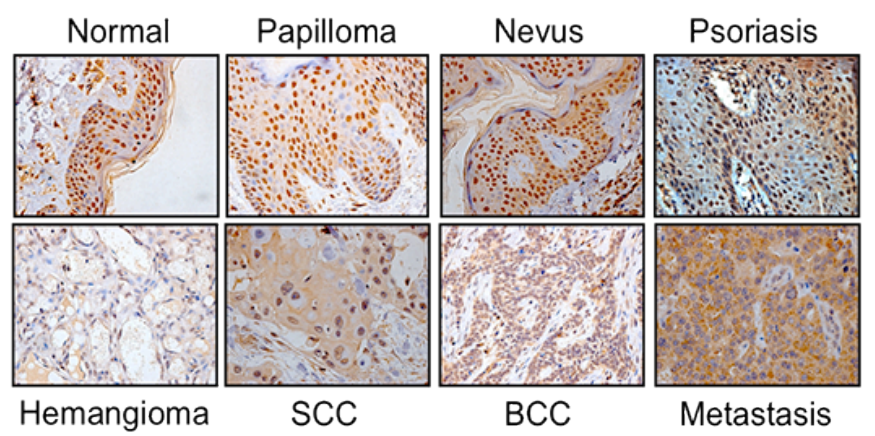

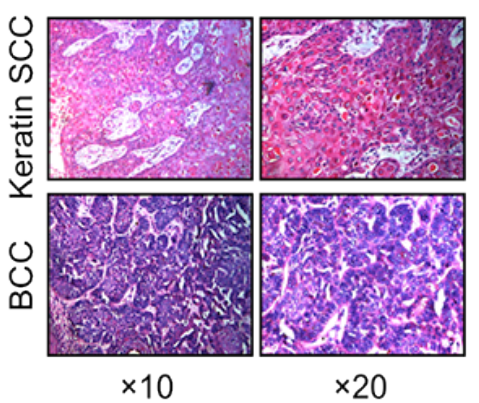

E
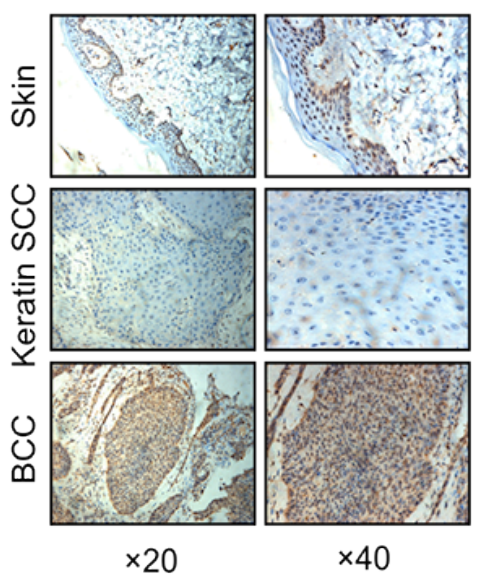

$\mathrm{F}$
C

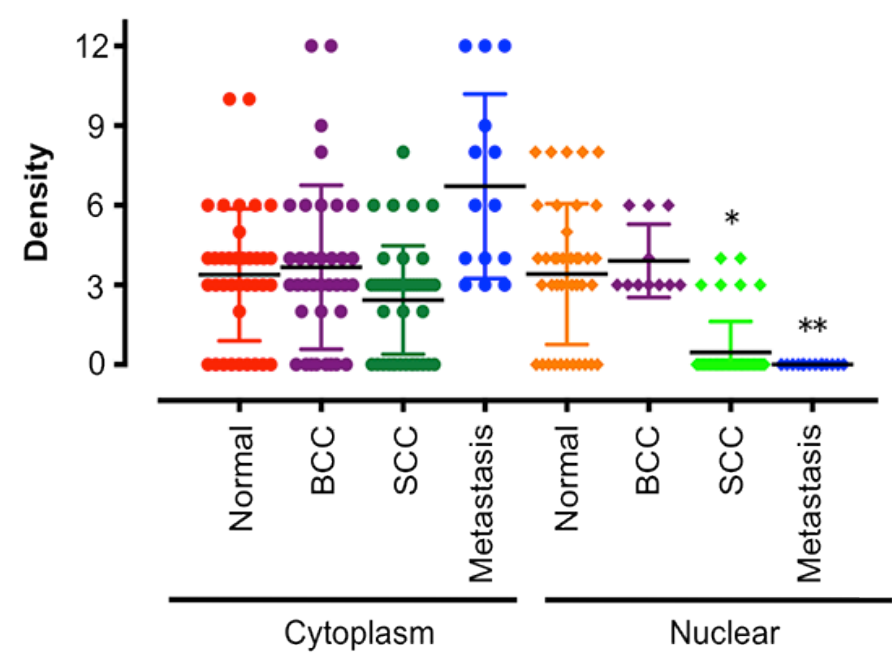

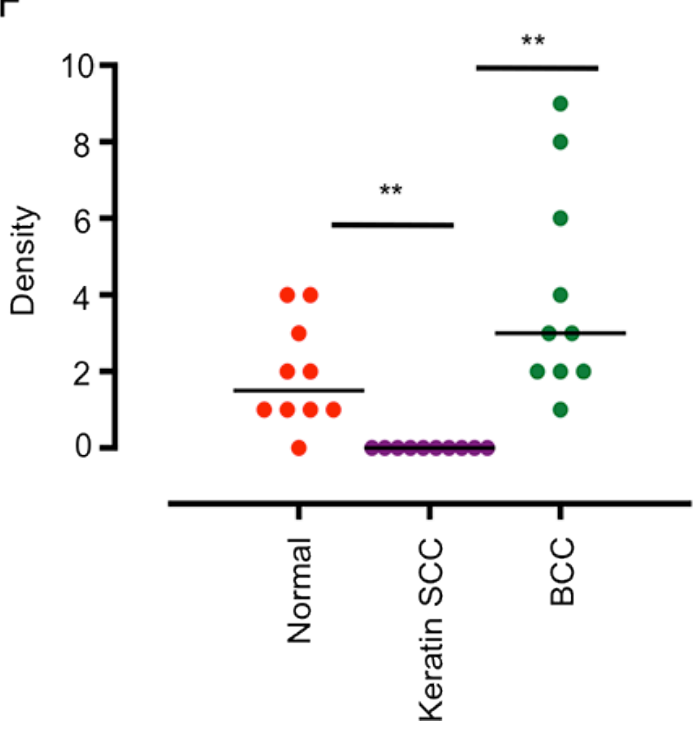

Figure 1: IKK $\alpha$ was dysregulated and delocalized in skin-related tumors. A.. Anti- IKK $\alpha$ staining intensity was quantified in three microscopic fields for each tissues section and expression level of IKK $\alpha$ in skin-related diseases as indicated. $n$, number of analyzed samples. B.. A series of tissues samples was subjected to IHC with IKK $\alpha$-specific antibody. The panels shown here were representative of IKK $\alpha$ staining in skin-related diseases as indicated. (Magnification: 40×.) C.. Distribution of IKK $\alpha$ in the cytoplasm and nucleus was quantified in BCC, SCC and metastasis. D. H \& E staining was used to show different tissue type of BCC and keratin SCC. E. Immunohistochemical analysis was used to examine the level of IKK $\alpha$ in BCC and keratin SCCs. F. Expression level of IKK $\alpha$ in normal skin, keratin SCC and BCC as indicated. * $p<0.05, * * p<0.01, * * * p<0.001$. 
IKK $\alpha$. Other proteins including p-STAT3, total STAT3 and LGR6 remained the same level (Figure 3A). Similar findings were found in A431 cells that were stable expression the inducible knockdown of IKK $\alpha$ system (Figure 3B), indicating that a strong correlation might exist in IKK $\alpha$ and LGR5.

To address the role of other members of IKK complex, we detected LGR5 expression after the depletion of IKK $\beta$ and IKK $\gamma$ with shRNA respectively. LGR5 expression did not change significantly after the depletion of IKK $\beta$ using two separate shRNA sequences (Left panel of Supplementary Figure S2), meanwhile LGR5 expression slightly decreasead after complete depletion of IKK $\gamma$ (Right panel of Supplementary Figure S2). Data indicated that both IKK $\beta$ and IKK $\gamma$ was not involved in the regulation of LGR5 expression.

To further confirm the correlation between IKK $\alpha$ and LGR5, we analyzed LGR5 expression in skin BCC and metastasis biopsies using IHC. LGR5 protein expression was greatly increased in BCC tumor samples as well as metastasis (Figure 3C). The evaluation of IKK $\alpha$ and LGR5 protein levels of all 35 biopsies conformed the positive correlation between IKK $\alpha$ and LGR5 ( $p<$ 0.01 ) (Figure 3D). Taken together, these results suggest that IKK $\alpha$ might be a major activating signal for LGR5 expression in $\mathrm{BCC}$.

\section{Inflammatory factors activate STAT3 signaling pathway that is controlled by IKKa}

Since the JAK-STAT pathway is possibly involved in BCC pathogenesis, EGF, IL-6 and Cxcl1 trigger STAT3 signaling pathway [26]. We first treated cells with inflammatory factors, and found that EGF, IL-6 and Cxcl1 increased cell proliferation. Also knockdown of IKK $\alpha$ reduced cell growth in the absence or presence of EGF, Il-6 and Cxcl1 in A431 cells (Figure 4A, Figure 4C and Figure 4E) and in HaCaT cells (Figure 4B, Figure 4D and Figure 4F). Taken together, data indicates that IKK $\alpha$ involves in STAT3 signaling pathway.

Next, we analyzed the potential role of STAT3 signaling pathway in LGR5 expression. We treated A431 cells that IKK $\alpha$ was depleted in an inducible manner with inflammatory factors. We found that IKK $\alpha$ was depleted after the treatment of Dox in the absence and presence of IL-6, Cxcl1 and EGF. Meanwhile, LGR5 protein level slightly decreased after knockdown of IKK $\alpha$ in the presence of IL-6, Cxcl1 and EGF, indicating that STAT3 signaling pathway might involve in the regulation of LGR5 (Figure 4G). However both total STAT3 and phospharylated STAT3 at tyrosine 705 (p-STAT3) remained the same level (Figure 4G), indicating that STAT3 might increase directly LGR5 expression.
A
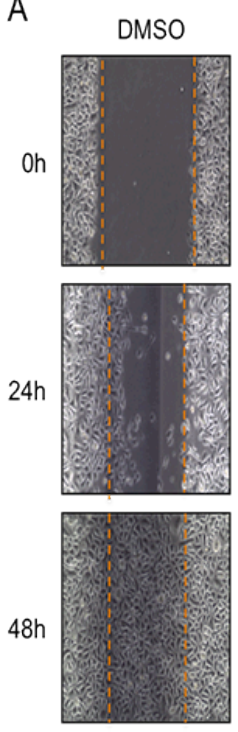

$72 \mathrm{~h}$

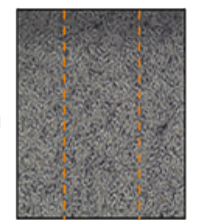

IKK-i XII
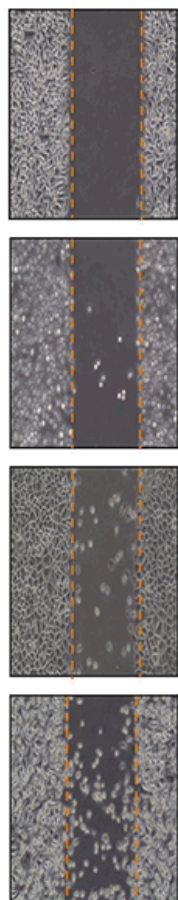

B
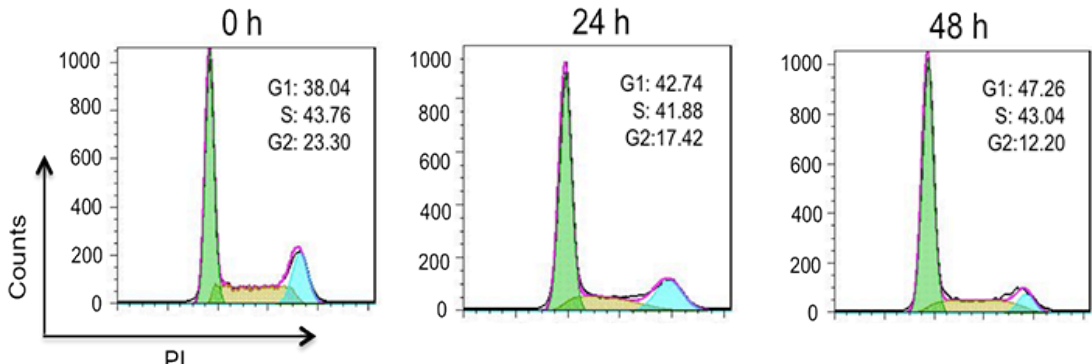

C

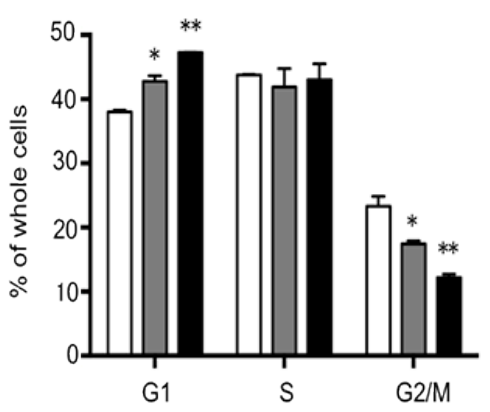

D

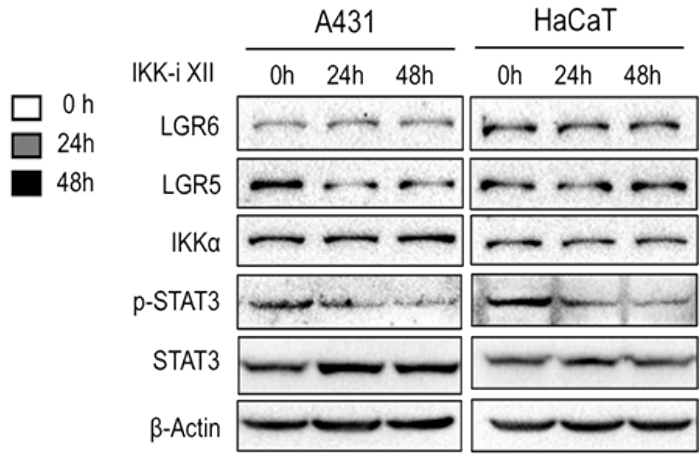

Figure 2: Inhibition of IKKa reduces LGR5 expression. A.. A431cells with the treatment of IKKi-II were analyzed for their ability to migrate in a wound healing assay at indicated time points. B.. FACS analysis was used to detect cell cycle progression in A431 cells after the treatment of IKKi-II. C.. Statics of FACS analysis in A431 cells after the treatment of IKKi-II. * $p<0.05, * * p<0.01$. D.. A431 (Left) and HaCaT (Right) with treatment of IKKi-II were examined for the expression of LGR6, LGR5, IKK $\alpha$, p-STAT3, STAT3 and $\beta$-actin by Western analysis. 


\section{Inhibiting STAT3 signaling pathway decreases LGR5 expression}

Stattic is a small molecule shown to selectively inhibit the activation of the STAT3 transcription factor by blocking phosphorylation and dimerization events. We found that Stattic decreased cell growth using an inducible knockdown of IKK $\alpha$ in both A431 and HaCaT cells, and we also showed that the combination of Stattic and knockdown of IKK $\alpha$ role in reducing cell growth in A431 cells (Figure 5A) and HaCaT cells (Figure 5B). Moreover, both IKKi-II and Stattic down-regulated significantly the LGR5 promoter transcription (Figure 5C).

Then we performed ChIP assay to address whether p-STAT3 involved in regulation of LGR promoter directly, we found that both IKKi-II and Stattic decreased the binding ability of p-STAT3 in the LGR5 promoter in $\mathrm{HaCaT}$ cells (Figure 5D and 5E). However, only IKKiII could not decrease the binding ability of p-STAT3 in the LGR5 promoter in A431 cells (Figure 5E). Moreover, knockdown of IKK $\alpha$ decreased the binding of p-STAT3

B HaCaT-799

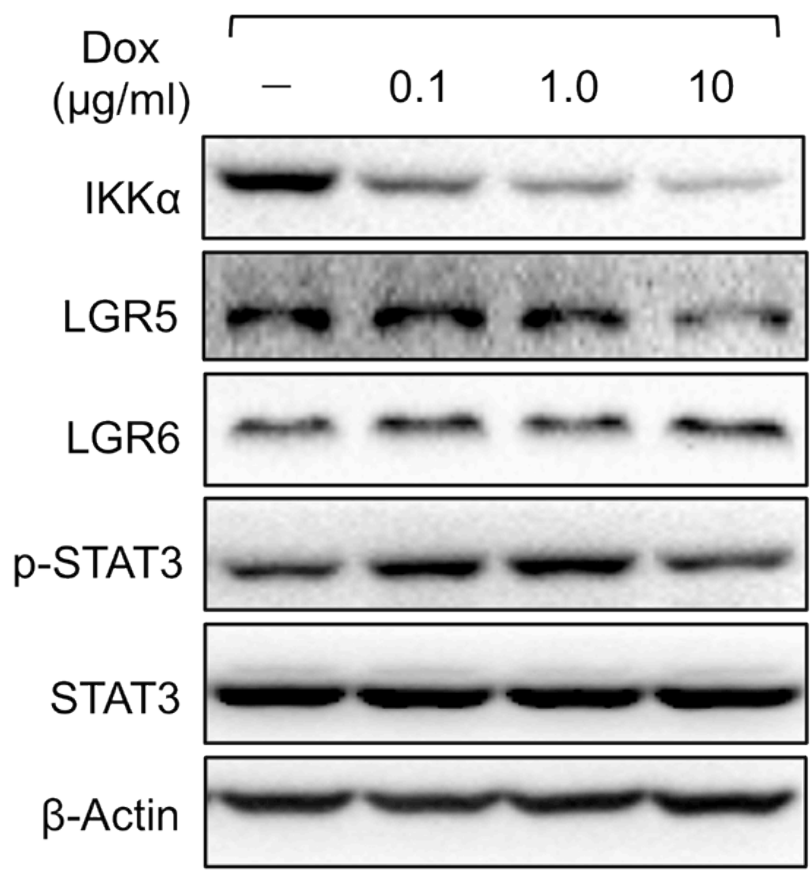

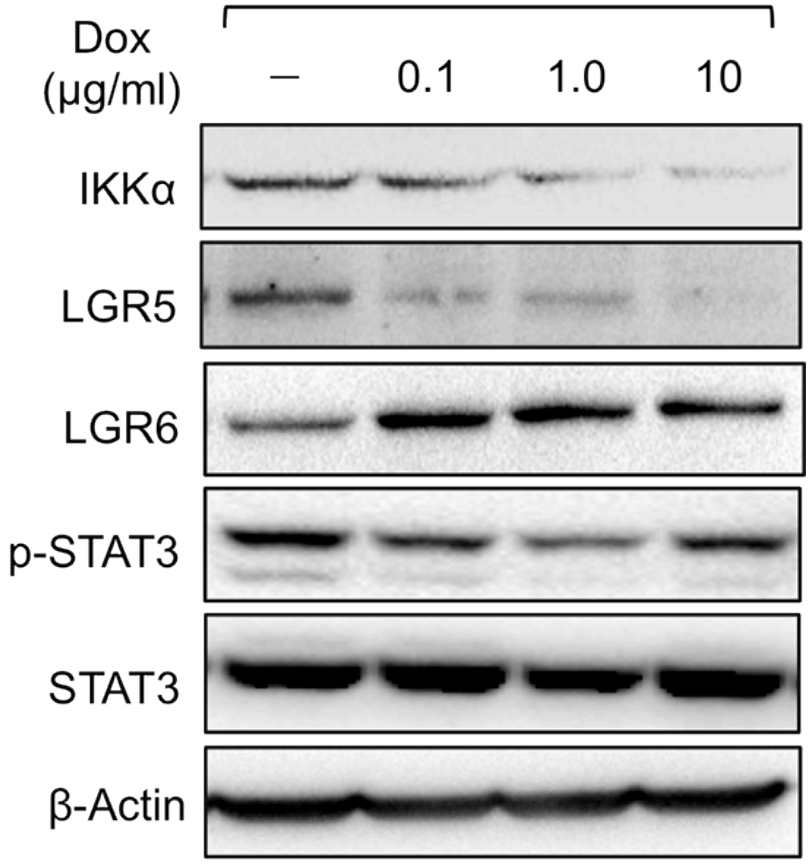

C

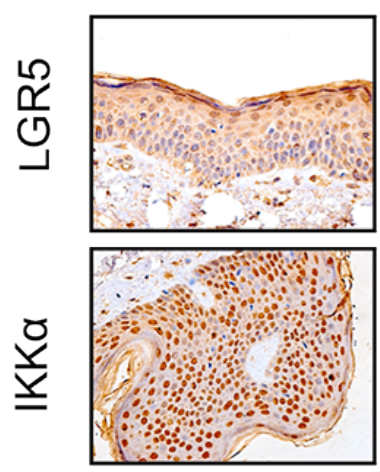

Normal

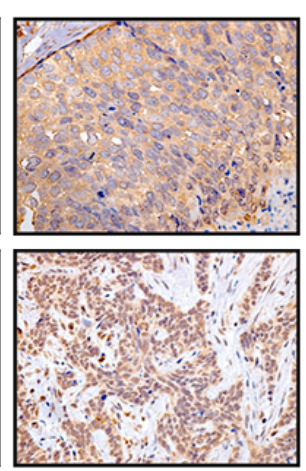

$\mathrm{BCC}$

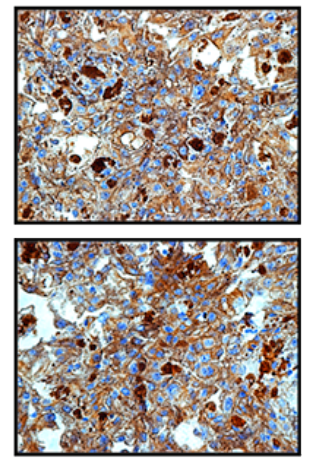

Metastasis

D

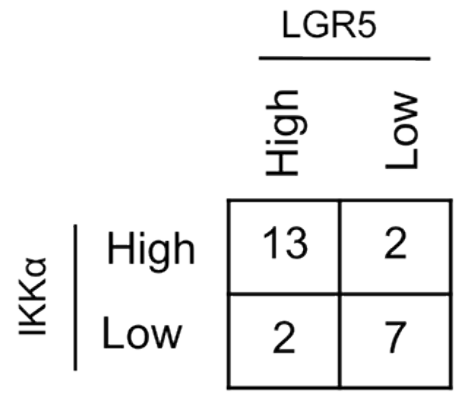

Figure 3: Knockdown of IKKa decreased LGR5 expression. A431 A. and HaCaT B. cells were examined for the expression of proteins as indicated by Western analysis after an inducible knockdown Tet-on system of IKK $\alpha$ the cells were stably transfected. C.. Immunohistochemical analysis was used to examine the level of LGR5 protein in skin-related diseases. LGR5 was expressed at high levels whereas IKK $\alpha$ was also expressed at higher levels in skin BCC tissues (Tumor, Metastasis). (Magnification: 40×.) D.. Summary of LGR5 and IKK $\alpha$ protein levels in 35 tissue samples. Fisher's test, two-tailed $p<0.01$. 
A

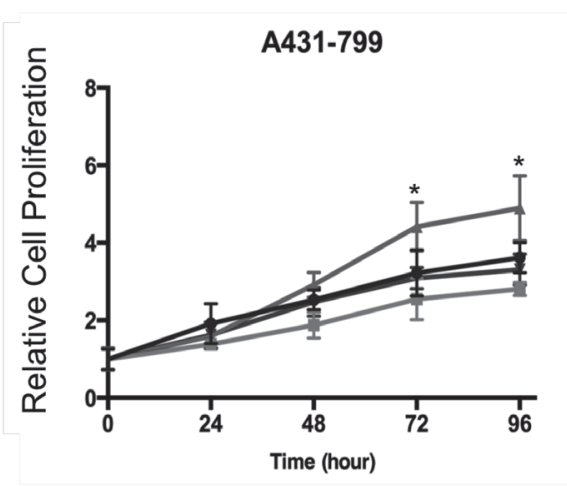

C

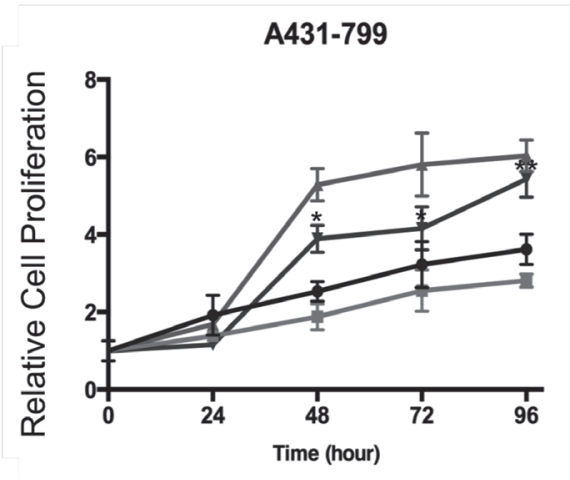

$E$

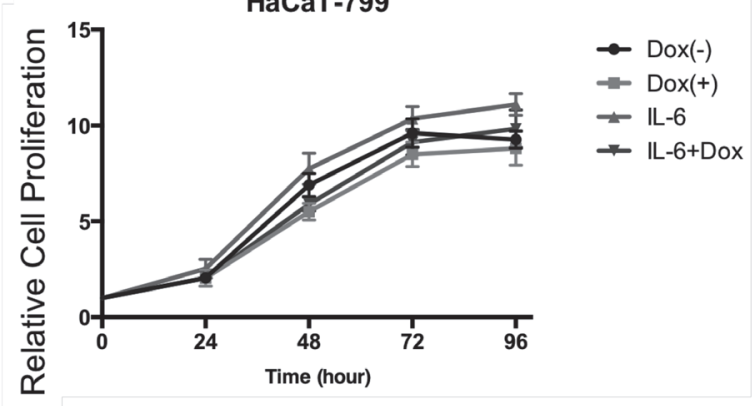

$\mathrm{B}$

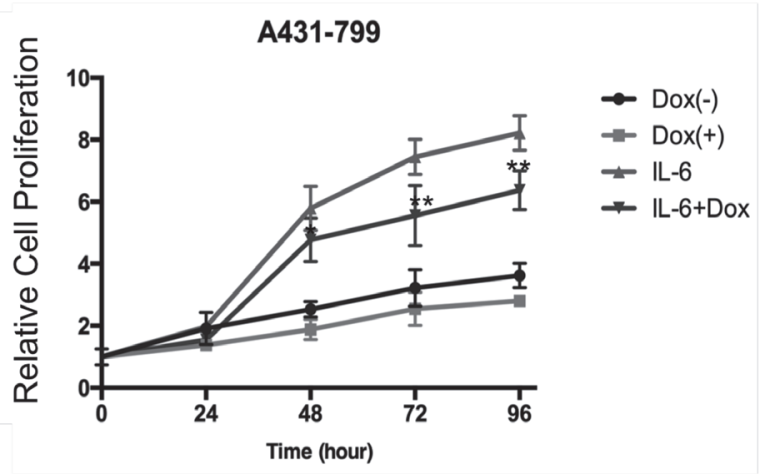

D
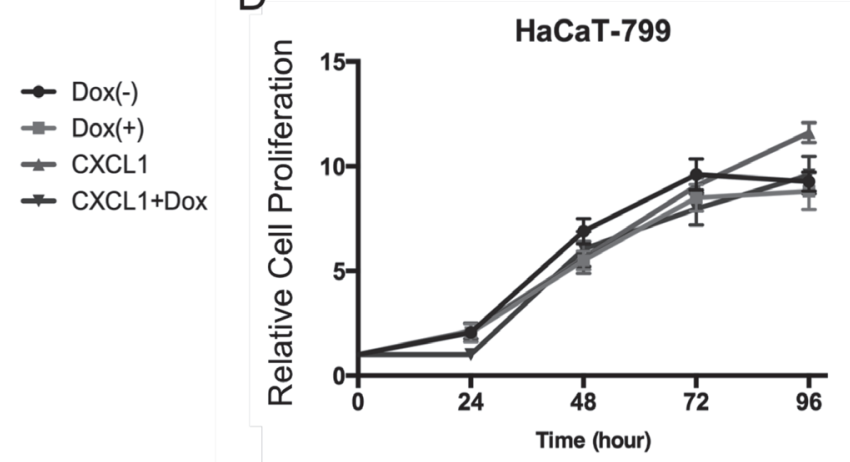

$$
\begin{aligned}
& \rightarrow \text { Dox }(-) \\
& =\text { Dox }(+) \\
& =\text { EGF } \\
& =\text { EGF+Dox }
\end{aligned}
$$

F

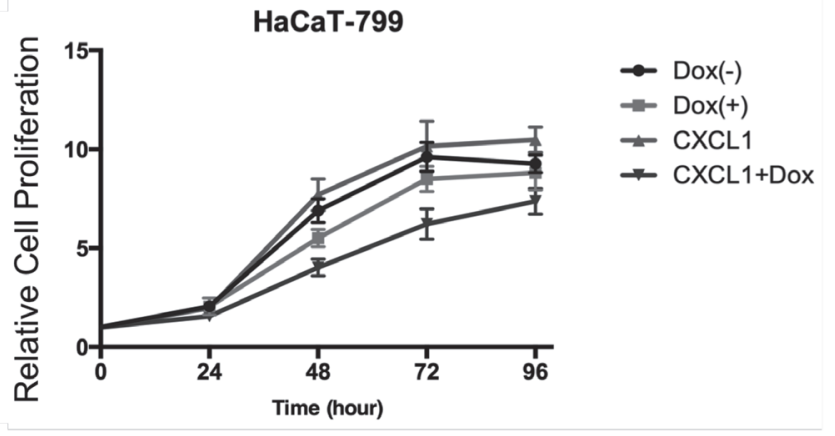

$\mathrm{G}$
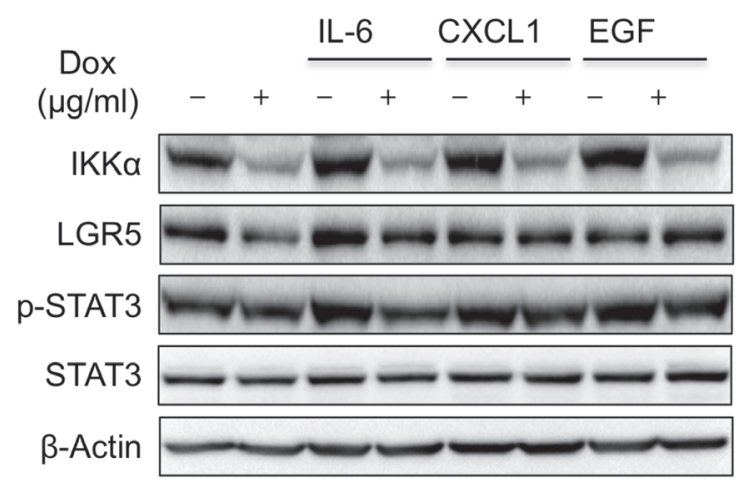

Figure 4: Inflammatory factors activated STAT3 signaling pathway that was controlled by IKKa. The MTT assay was performed to assess cell viability in A431 cells that were stably transfected with an inducible Tet-on IKK $\alpha$ shRNAs and the cells were treated with EGF A., IL-6 C., and Cxcl1 E. The MTT assay was performed to assess cell viability in HaCaT cells that were stably transfected with an inducible Tet-on IKK $\alpha$ shRNAs and the cells were treated with EGF B., IL-6 D., and Cxcl1 F.. G.. A431 cells with an inducible knockdown Tet-on system of IKK $\alpha$ were examined for the expression of proteins as indicated by Western analysis after the treatment of inflammatory factors for $24 \mathrm{~h} . * p<0.05, * * p<0.01$. 
to LGR5 promoter (Figure 5E). Lastly, we treated both $\mathrm{HaCaT}$ and A431 cells with Stattic as time indicated, both p-STAT3 phospharylation level and LGR5 protein level decreased (Figure 5F), indicating that activated STAT3 controlled LGR5 expression directly.

\section{IKK $\alpha$ directly targets to the inflammatory factors and LGR5}

Since IKK $\alpha$ plays a critical role inflammation, we addressed whether IKK $\alpha$ could affect inflammatory factor directly. We detected mRNA level of EGF, IL-6 and Cxcl1 after the knockdown of IKK $\alpha$ in an inducible system. We found that IKK $\alpha$ mRNA reduced to less than $40 \%$ after the treatment of Dox for $48 \mathrm{~h}$ in A431 cells, and mRNA levels of EGF, IL-6 and Cxcl1 decreased significantly (Figure 6A). Similar findings were shown in HaCaT cells after knockdown of IKK $\alpha$ (Figure 6B). Furthermore, we treated both A431 and HaCaT cells with IKK-i II for $48 \mathrm{~h}$, and we found that mRNA levels of EGF, Cxcl1 and IL-6 decreased significantly, while Cxcl1 mRNA level reduced to less than $10 \%$ (Figure $6 \mathrm{C}$ ), indicating that IKK $\alpha$
A

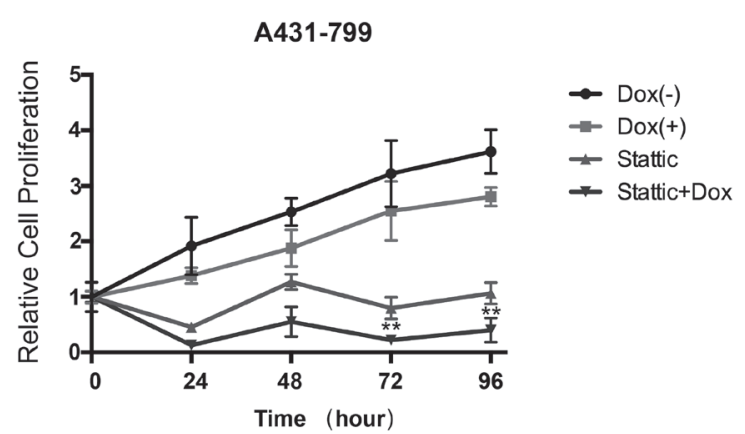

C

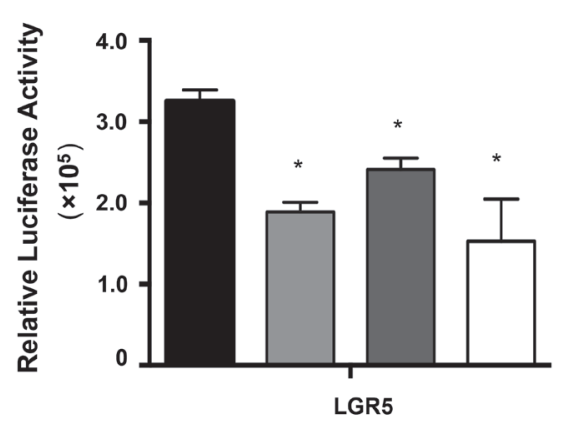

$E$

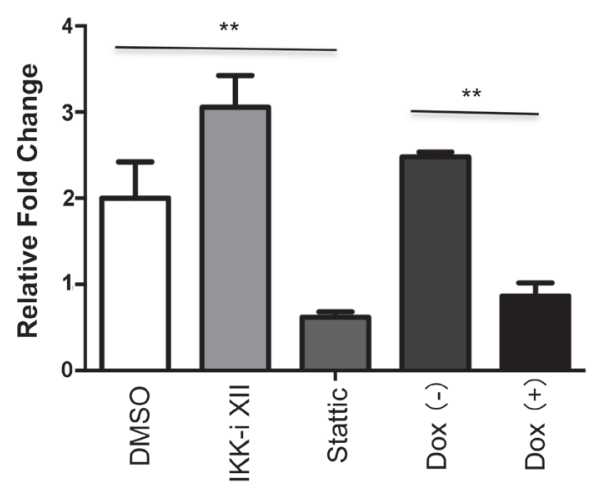

B

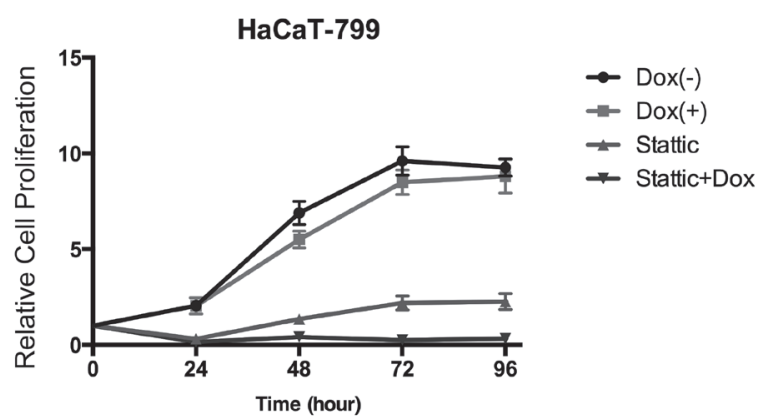

D

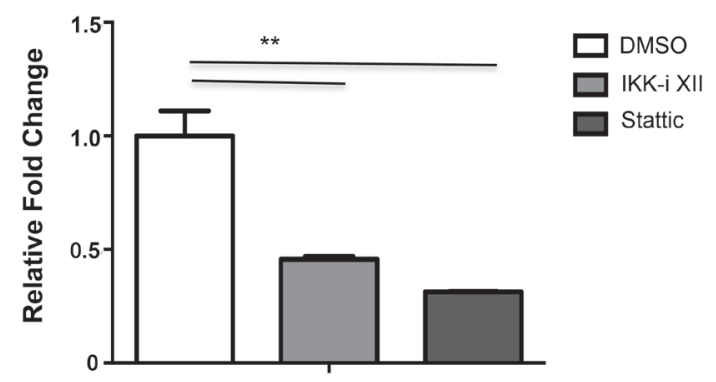

$\mathrm{F}$

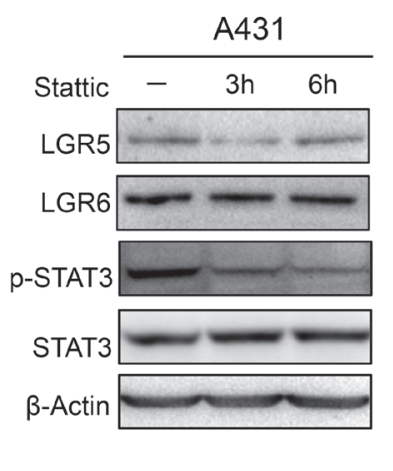

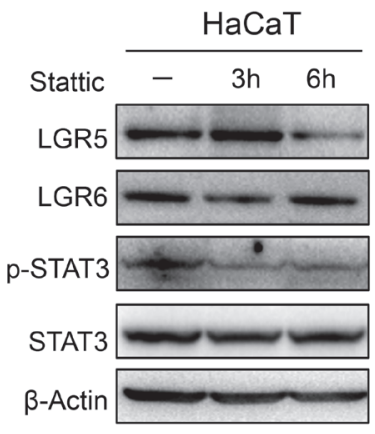

Figure 5: Activation of STAT3 signaling pathway was involved in the regulation of LGR5 expression. The MTT assay was performed to assess cell viability in A431 cells A. and HaCaT cells B. that were stably that were stably transfected with an inducible Tet-on IKK $\alpha$ shRNAs and the cells were treated with Stattic. C.. A luciferase reporter assay was carried out to evaluate LGR5 promoter activity in 293 cells after the treatment of IKKi-II and/or Stattic. All promoter luciferase intensity was normalized to the pRL renilla luciferase control reporter. ${ }^{*} p<0.05,{ }^{*} p<0.01$. D. ChIP analysis in HaCaT cells and chemicals treatment indicated was performed to detect p-STAT3 binding to LGR5 gene. E.. ChIP analysis in A431 cells after Tet-on shIKK $\alpha$ transfected and chemicals treatment indicated was performed to detect p-STAT3 binding to LGR5 promoter gene. F.. A431 (Left) and HaCaT (Right) with treatment of Stattic were examined for the expression of selected proteins by Western analysis. ${ }^{* *} p<0.01$ 
involves in the control of these inflammatory factors.

To address whether IKK $\alpha$ links with LGR5 expression, we constructed a report gene of LGR5 that 1077 bp of LGR5 promoter was inserted into pGL4.16. After we transfected LGR5 reporter gene into 293 cells and treated the cells with the chemicals indicated for 72 $\mathrm{h}$, and we found that both IKKi-II and Stattic decreased LGR5 promoter transcription while EGF slightly increased the transcription of LGR5 promoter (Figure 6D and Supplementary Figure S3). As IKK $\alpha$ could locates in nucleus and functions as a chromatin modifier [27, 28], we addressed whether IKK $\alpha$ involved in the regulation of inflammatory factors and LGR5 directly. We performed ChIP assay in A431 cells after the treatment of both IKKiII and Stattic, we amplified the potential binding site of IKK $\alpha$ in the promoter of inflammatory genes and LGR5 as indicated in supplementary Figure S4 using real-time PCR. We found that IKK $\alpha$ bound to the promoter regions of EGF, IL- 6 and $\mathrm{CxCl1}$ and we also showed that IKK $\alpha$ was enriched in the promoter of LGR5 (Figure 6E), indicating that IKK $\alpha$ controls the inflammatory genes and LGR5 directly. On the basis of this, we wondered whether both IKK $\alpha$ and STAT3 formed an intact complex, we found that IKK $\alpha$ might interact with STAT3 in A431 cells
(Figure 6F). To further address the role of LGR5 in skin carcinogenesis, we generated stable LGR5 knockdown in A431 cells using a set of shLGR5 lentivirus vectors (see 'Material and Method' section) (inlet of Figure 6G). The knockdown of LGR5 resulted in significantly reduced growth of A431 cells in culture (Figure 6G) and tumor weight after seeding $3 \times 10^{6}$ of A431 cells (with or without LGR5 knockdown) into nude mice (Figure 6H).

\section{IKK $\alpha$ affects tumor growth in vivo}

To further validate the physiological role of IKK $\alpha$ in BCC carcinogenesis, we generated stable IKK $\alpha$ knockdown in A431 cells in vivo. We injected $3 \times 10^{6}$ of A431 cells (with or without IKK $\alpha$ knockdown) into nude mice, and observed that IKK $\alpha$ depletion significantly impaired the tumor volume (Figure 7A), tumor formation (Figure S5A) and tumor weight (Figure S5B), while the body weight did not change significantly in either groups (Figure S5C). We confirmed the tumor formation using $\mathrm{H}$ \& E staining (Figure 7B)

Next, using immunohistochemistry staining, we found that the levels of IKK $\alpha$, Ki67, gp130, p-STAT3 and
A

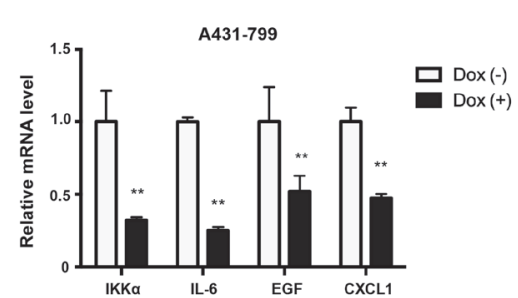

D

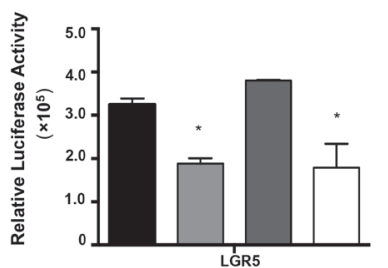

$\mathrm{F}$

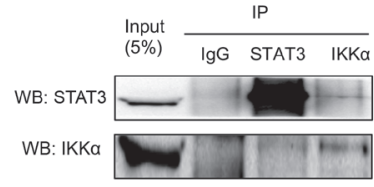

G
B
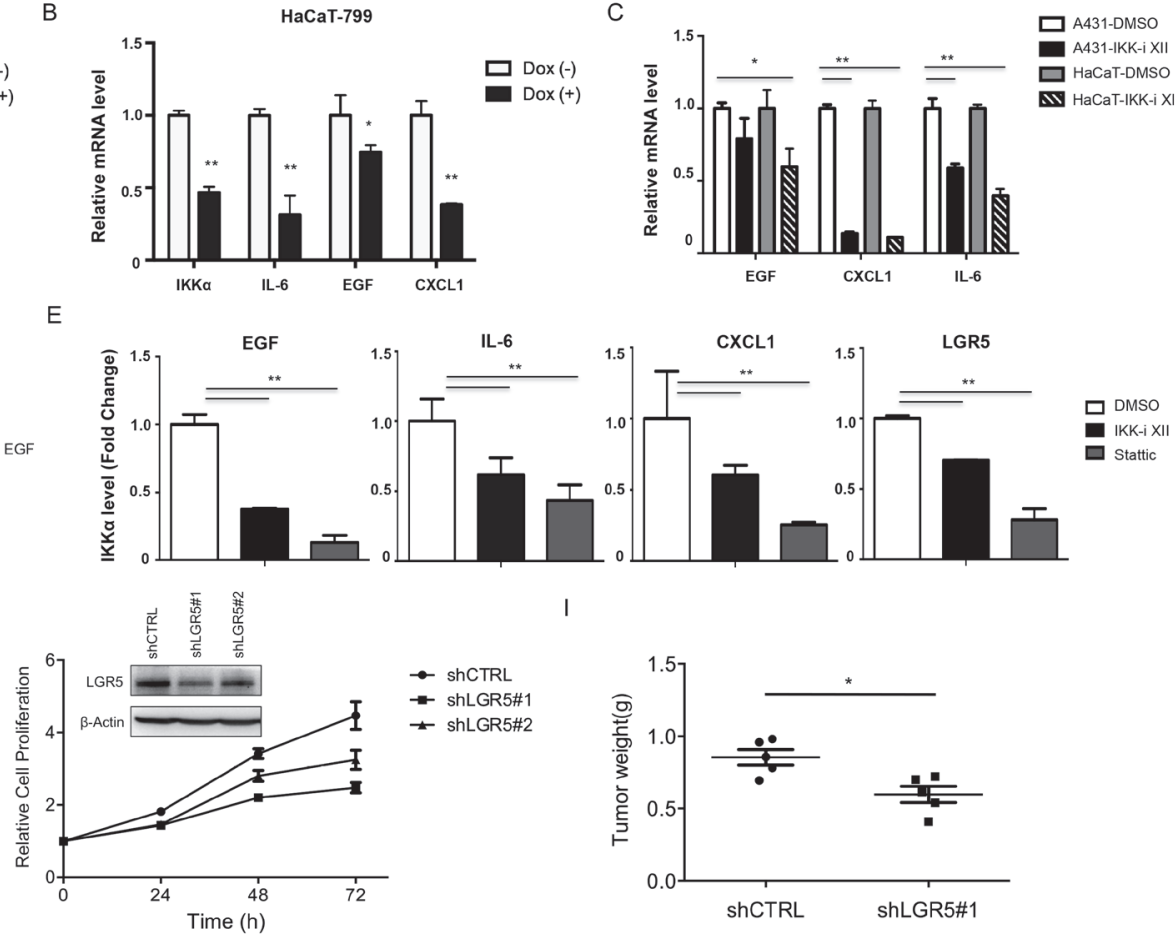

C

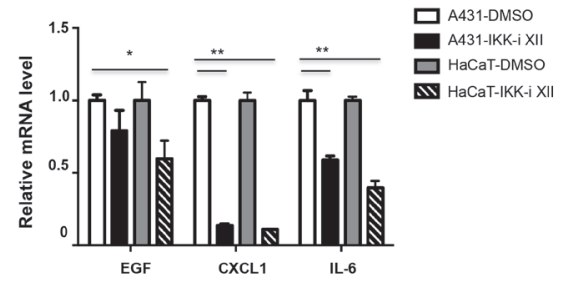

I

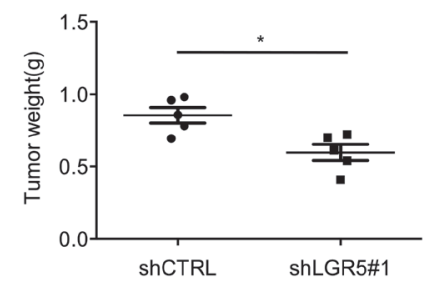

Figure 6: IKKa targeted to the inflammatory factors and LGR5. RT-PCR analysis was conducted to detect selected inflammatory factors using total RNA obtained from A431 cells A. and HaCaT cells B. after Tet-on shIKK $\alpha$ transfected. C. RT-PCR analysis was conducted to detect selected inflammatory factors using total RNA obtained from both HaCaT and A431 cells after the treatment of IKK-I II. D.. A luciferase reporter assay was carried out to evaluate LGR5 promoter activity in 293 cells. All promoter luciferase intensity was normalized to the pRL renilla luciferase control reporter. E.. ChIP analysis of A431 cells and chemicals treatment indicated was performed to detect IKK $\alpha$ binding to selected genes. F. Co-IP detected the intact complex of IKK $\alpha$ and STAT3 G. Cell proliferation in A431 was performed after the knockdown of LGR5. LGR5 protein levels, as detected by Western analysis, were shown in the inlet figure. H. A xenograft model of tumor weight was established in nude mice to evaluate the ability of knockdown of LGR5 in A431 cells and shCTRL cells to form cells. $* p<0.05, * * p<0.01$. 
A

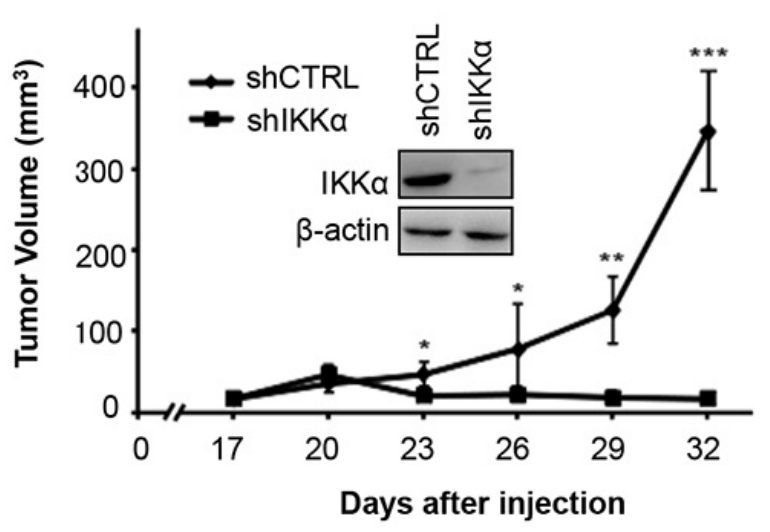

C

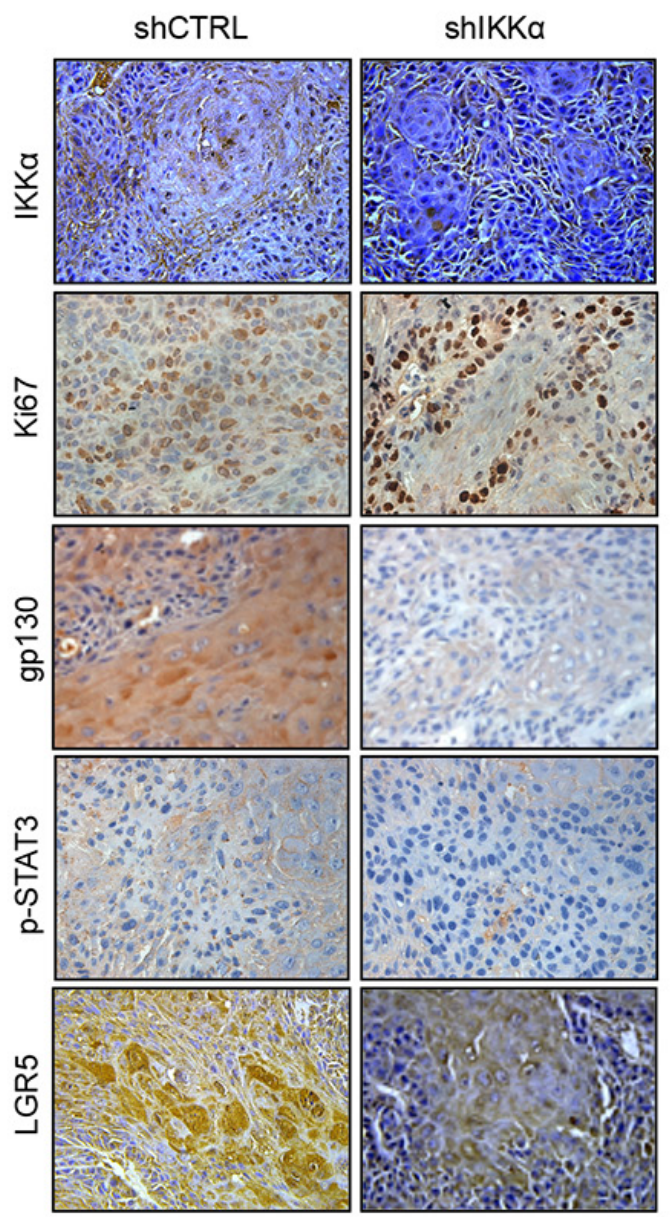

B
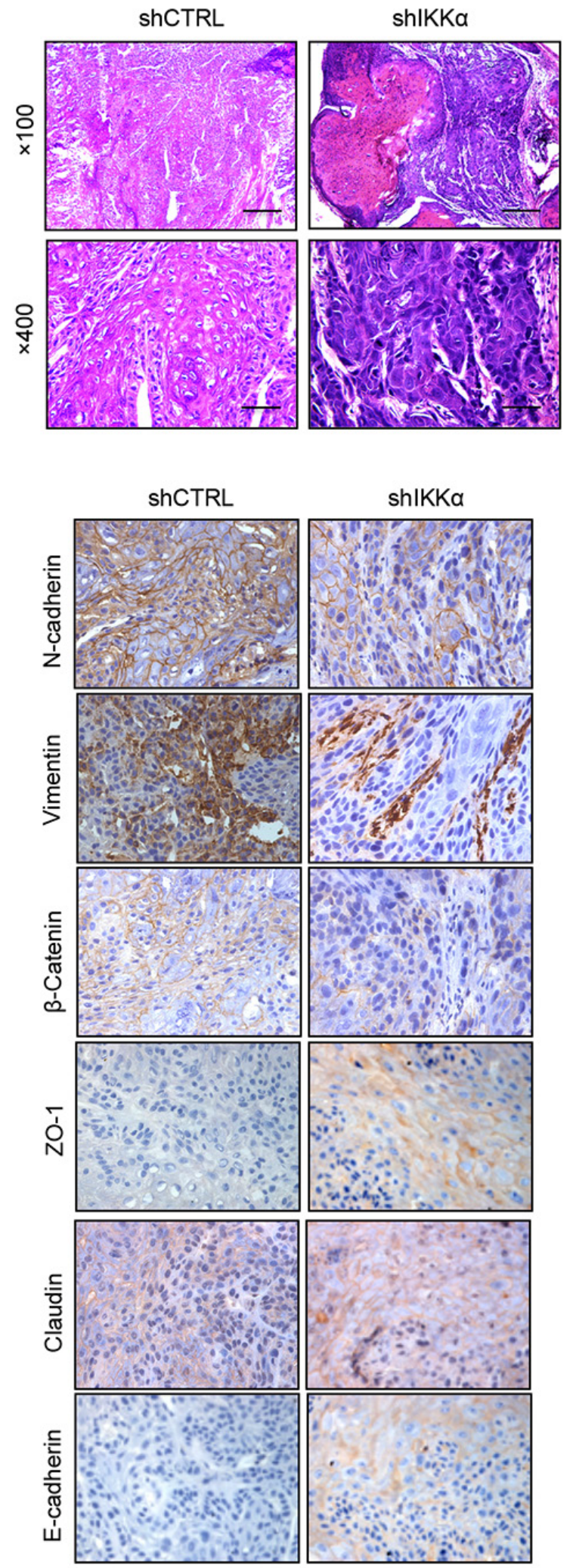

Figure 7: Inhibition of IKKa reduced tumor growth in vivo. A.. A xenograft model of tumor growth was established in nude mice to evaluate the ability of knockdown of IKKa in A431 cells and shCTRL cells to form cells. IKKa protein levels, as detected by Western analysis, were shown in the inlet figure. ${ }^{*} p<0.05, * p<0.01, * * * p<0.001$. B.. Tumor status was analyzed by $\mathrm{H} \& \mathrm{E}$ staining. C. Immunohistochemical analysis was used to examine the level of IKK $\alpha$, Ki67, gp130, p-STAT3 and LGR5 in tumor samples from nude mice. (Magnification: 40×.) D.. Immunohistochemical analysis was used to examine the level of EMT markers as indicated in tumor samples from nude mice. (Magnification: 40×.). 
LGR5 decreased in biopsies from transplanted nude mice after the depletion of IKK $\alpha$ (Figure 7C). Since LGR5 is linked with epithelial-mesenchymal transition (EMT) in normal stem cell, we addressed whether EMT happened in the depletion of IKK $\alpha$. Finally, we found that depletion of IKK $\alpha$ decreased the expression level of the mesenchymal markers (N-cadherin, Vimentin and $\beta$-catenin), while the epithelial markers (Claudin, ZO-1 and E-cadherin) decreased in the knockdown of IKK $\alpha$ (Figure 7D). Taken together, these findings indicate that the interplay between STAT3 and IKK $\alpha$ plays vital roles in BCC.

\section{DISCUSSION}

The reports from different groups indicate that there is an opposed effect of IKK $\alpha$ in several types cancer in carcinogenesis [29-35]. Recently, we show that IKK $\alpha$ is diversely expressed in keratinizing and non-keratinizing carcinomas in the same type of cancer [36]. Here we firstly provide evidence that IKK $\alpha$ is absence in SCC of skin while is expressed in $\mathrm{BCC}$, indicating the opposed roles of IKK $\alpha$ in skin cancer between SCCs and BCCs, which are origin from both keratinocyte tumors. Moreover, we provide evidence that IKK $\alpha$ promotes EMT that is an unintentional behavior of cells during cancer progression $[37,38]$. One significant difference between SCC and $\mathrm{BCC}$ is that SCC development is generally associated with cell dedifferentiation that IKK $\alpha$ is reversely involved in the process.

The cellular origin of $\mathrm{BCCs}$, the great majority of skin cancer, arises from hair follicle stem cells, mechanosensory niches and multiple epithelial progenitor populations [39-41]. In the skin, multiple stem cell populations in the hair follicles and epidermis maintain tissue homeostasis and contribute to organ regeneration; furthermore, cancer stem cells (CSCs) have been purified and characterized from mouse multiple hair follicle [40, 42]. Dysregulated hedgehog $(\mathrm{HH})$ signaling is a hallmark of $\mathrm{BCC}$, and cilia have a dual role in mediating both the activation and the repression of the $\mathrm{HH}$ signaling pathway [17, 43]. LGR5, a marker of intestinal stem cells, maintains hair follicle stem cells by autocrine $\mathrm{HH}$ signaling [2]. We show that LGR5 protein is expressed in both BCCs and SCCs, moreover LGR5 is up-regulated by high level of IKK $\alpha$ in BCCs. Similar findings have been reported increasing LGR5 mRNA levels in BCCs using real-time quantitative RT-PCR analysis [3, 44]. However, we did not found that side population cells increased significantly in A431 cells (Figure S6).

Beyond $\mathrm{HH}$ signaling pathway, recently other signaling pathways such as STAT3 signaling pathway involve in BCCs carcinogenesis [45, 46], during the development of ultraviolet (UV) B skin tumors, STAT3 plays a critical role in both survival and proliferation of keratinocytes [47]. In addition, JAK-STAT pathway is possibly involved in $\mathrm{BCC}$ pathogenesis from expression- associated single-nucleotide polymorphisms using genome-wide association study of BCCs [26]. Our findings further demonstrated that activated STAT3 involved in BCCs carcinogenesis through targeting LGR5 promoter directly, meanwhile, several inflammation factors also stimulated the activation of STAT3 signaling pathway. Meanwhile, IKK $\alpha$ located in the nucleus and bound to the promoters of inflammation factors, in turn, increasing the expression levels of these factors, which could act in a paracrine manner around their environments. The signaling pathways between NF- $\kappa \mathrm{B}$ and STAT3 cooperate to promote the development and progression of colon, gastric and liver cancers as a central signaling hubs in inflammation-mediated tumors [48-50]. Here we provide evidence that both IKK $\alpha$ and STAT3 involved in LGR5 expression in BCCs, while inflammation factors linked with the interplay.

Recent reports show that receptor binding by LIF1, IL-6 and related cytokines engages both gp130Yes-YAP module and gp130-Src-Yap axis, stimulates self-renewal of cultured embryonic stem cells and links with inflammation to epithelial regeneration respectively $[51,52]$, indicating the potential interplay of signaling pathway between gp130-STAT3 and YAP-hedgehog $(\mathrm{HH})$ module. In BCC, we first provide evidence the interplay role of gp130-STAT3 pathway on LGR5, a direct target of HH signaling pathway, is stimulated by IL-6 and other members of the IL-6 family member and a direct link between HH-LGR5 and gp130-STAT3 exist in BCC.

In addition, IKK $\alpha$ comprises a nuclear localization signal and therefore also confers important nuclear functions. In the nucleus, IKK $\alpha$ forms an intact complex with CREB binding protein (CBP) and contributes to NFאB promoted gene expression through phosphorylation of histone H3 [27, 28, 53]. Additional tumor-promoting nuclear functions of IKK $\alpha$ include cell cycle regulation and chromosomal accessibility as a chromatin modifier $[54,55]$. Here, we show that the intact complex of IKK $\alpha$ and STAT3 could regulate the LGR5 and inflammatory factors in BCC. Moreover, we show that IKK $\alpha$ might control EMT through LGR5 pathway.

In summary, based both on the expression level of IKK $\alpha$ in skin-related cancers and on the impact of LGR5 on BCC tumorigenesis, we conclude that IKK $\alpha$ is not expressed in skin SCC but in the nucleus of skin BCC and skin related non-malignant diseases. Activation of STAT3 signaling pathway contributes LGR5 expression in dependent of IKK $\alpha$. Knockdown of IKK $\alpha$ in cancer cells inhibits tumor growth and transition of epithelial stage to mescheme stage. Our findings provide that the interplay between STAT3 and IKK $\alpha$ plays vital roles in BCC. 


\section{MATERIALS AND METHODS}

\section{Antibodies, plasmids, siRNAs, chemicals and cell cultures}

Primary antibodies ZO-1, E-cadherin, Vimentin, $\beta$-catenin, Ki67, gp130, IKK $\alpha$,STAT3, p-STAT3(Y705) for $\mathrm{IHC}$ analysis and Western Blot were purchased from Cell Signaling (Danvers, MA). Primary antibody for LGR5 and $\beta$-actin were purchased from Sigma-Aldrich (St. Louis, MO). Primary antibodies for LGR6 was purchased from Millipore (Temecula, CA).

The TRC-shLSH lentivrus plasmids, shIKK $\alpha$, $\operatorname{shIKK} \beta, \operatorname{shIKK} \gamma$ and LGR5 and Tet-on $\operatorname{shIKK} \alpha$ were purchased from from Genechem (www.genechem.com. $\mathrm{cn}$ ). The IKK $\alpha$ inhibitor (IKKi-II) was purchased from Selleck. The STAT3 inhibitor V, Stattic, was purchased from Millipore.

HaCaT, A431 and HEK293 cell line were purchased from the American Type Culture Collection (ATCC; Manassas, VA), and were cultured in DMEM (GIBCO, Life Technologies, Basel, Switzerland) medium with fetal bovine serum (FBS) to a final concentration of $10 \%$. All cell lines were maintained at $37^{\circ} \mathrm{C}$ with $5 \% \mathrm{CO}_{2}$.

\section{FACS}

Flow cytometry was used to quantify cells in each phase of the cell cycle. Cells $\left(2 \times 10^{5}\right)$ were plated into 6-well plates and treated with $40 \mu \mathrm{g} / \mathrm{mL}$ of IKK $\alpha$ inhibitor. Cells were harvested at 0,24 , and $48 \mathrm{~h}$, and washed twice with PBS. Pellets were resuspended in $0.5 \mathrm{~mL}$ PBS, fixed in $4.5 \mathrm{~mL}$ of $70 \%$ ethanol, and incubated overnight at $4^{\circ} \mathrm{C}$. To detect the fluorescent intensity of certain proteins, cells were counterstained in the dark with $50 \mu \mathrm{g} / \mathrm{mL}$ of phosphatidyl inositol (PI) and $0.1 \%$ ribonuclease A (RNase A) in $400 \mu \mathrm{l}$ of PBS at $25^{\circ} \mathrm{C}$ for $30 \mathrm{~min}$. Stained cells were assayed and quantified using a FACSort Flow Cytometer (Becton Dickinson, U.S.A).

\section{Wound-healing assay and MTS assay}

The cultured cells were grown in 6-well plates until confluent. A scrape was made through the confluent monolayer with a plastic pipette tip of $1 \mathrm{~mm}$ diameter. Afterwards, the dishes were washed twice and incubated at $37^{\circ} \mathrm{C}$ in fresh RPMI containing $10 \%$ fetal bovine serum in the presence or absence of $40 \mu \mathrm{g} / \mathrm{mL}$ of IKK $\alpha$ inhibitor. At the bottom side of each dish, two arbitrary places were marked where the width of the wound was measured with an inverted microscope. Cell motility was expressed as the mean $+/$ - SEM of the difference between the measurements at $0,24,48$ and $72 \mathrm{~h}$ after wound.
Cell viability was measured using a CellTiter-Glo Luminescent Cell Viability Assay Kit (MTS) purchased from Promega Corp (Madison, WI) and used according to the manufacturer's protocol. At $24 \mathrm{~h}$ post-transfection with $50 \mathrm{ng} / \mathrm{mL}$ of EGF or $50 \mathrm{ng} / \mathrm{mL}$ of IL-6 in the presence or absence of $1 \mu \mathrm{g} / \mathrm{mL}$ Dox induced, cells were seeded into 96-well plates $\left(2 \times 10^{3}\right.$ cells/well $)$, and cell proliferation was recorded every $24 \mathrm{~h}$ for 4 days. Measuring the absorbance at $450 \mathrm{~nm}$ using a microplate reader assessed the number of viable cells.

\section{Transient transfection and luciferase reporter assay}

We cloned a regulatory region of the human LGR5 gene. A 1077-bp (-754 +324) nucleotide sequence was amplified by PCR using the following primers: 5'-GGGGTACCTCTGTCACTCTGGCATCGATT-3' and 5'-CCCAAGCTTAAGGACAGGAGCACACCGAGC-3'. Forward primer contained HindIII restriction site and the reverse primer harbored a $K p n I$ restriction site and a few additional nucleotides before the restriction sites. The PCR product was digested with HindIII and KpnI, subcloned into the reporter vector pGL4.16 (Promega) to generate a reporter construct.

The LGR5 promoter luciferase reporter construct was created by cloning the LGR5 promoter (1077 bp) into the pGL4.16 vector (Promega), driving the expression of firely luciferase. For transfection, 800 ng pGL4.16 or putative LGR5 promoter luciferase plasmid and combinations of IKK $\alpha$ inhibitor were used along with pRL-SV40 (from Promega) plasmid for normalization of transfection efficiencies. $24 \mathrm{~h}$ after transfection, cells were harvested at $36 \mathrm{~h}$ after transfection and lysates were analyzed for luciferase activity using the Dual Luciferase Reporter assay (Promega) according to the manufacturer's directions with a GloMax ${ }^{\mathrm{TM}}$ Microplate Luminometer (Promega). The data represent the mean \pm SD of the three independent experiments performed in triplicate.

To observe EGF, Stattic and CXCL1 afftecting the activities of LGR5, $24 \mathrm{~h}$ after transfection, cells were treated with $50 \mathrm{ng} / \mathrm{mL}$ of EGF (Invitrogen), $50 \mathrm{ng} / \mathrm{mL}$ of Stattic (Cell Signalling Technology, U.S.A.), or $50 \mathrm{ng} /$ $\mathrm{mL}$ of CXCL1 (PreTech) for $24 \mathrm{hr}$. Cells were harvested at $48 \mathrm{~h}$ after transfection and subjected to the luciferase assay. Empty firefly reporter vector served as the negative control.

\section{Immunohistochemistry (IHC) analysis}

Skin and related diseases biopsies, validated by pathologist Dr. Desheng Xiao (Xiangya Hospital), were obtained from Pathology Department of Xiangya Hospital. The skin tissue array was purchased from Pantomics (Richmond, CA, USA). IHC analysis of paraffin sections 
from skin tissues or xenograft samples was described previously [56]. The sections were incubated with antibodies as indicated. The images were surveyed and captured using a CX41 microscope (OLYMPUS, Tokyo, Japan) with the Microscope Digital Camera System DP-72 (OLYMPUS, Tokyo, Japan) and differentially quantified by two pathologists who were from the Second Xiangya Hospital, Changsha, China.

IKK $\alpha$ staining was considered positively by ascertaining cytoplasmic and nuclear expression. The determination result was obtained from semi-quantitative classification according to 10 more visual fields $(\times 200)$. The slides were first scored as 0 (negative), 1 (buff), 2 (pale brown), and 3 (tan). Positive expression of IKK $\alpha$ were scored as 0 (negative), $1+(<10 \%$ of positivelystaining tumor cells), $2+(11-50 \%$ of positively-staining tumor cells), $3+(50-75 \%$ of positively-staining tumor cells), and $4+(>75 \%$ of positively-staining tumor cells. Both the scores by multiply were regarded as the determination result.

\section{Quantitative real-time PCR}

Cells were harvested with Trizol(Invitrogen). cDNAs were synthesized with SuperScript II (Invitrogen) according to the manufacturer's protocol. Realtime PCR analysis was performed using the Applied Biosystems 7500 Real-Time PCR System, according to the manufacturer's instructions. The reactions were performed in triplicate for three independent experiments: the results were normalized to $\beta$-actin. The primer sequences used were used in the following, EGF, mRNA forward primer, 5' - GCACCCTTCTTAATTTTCTCCCA -3'; reverse primer, 5' - TCTCTCTTGCCTTGACCCATT -3'; Il-6 forward primer, 5' ACTCACCTCTTCAGAACGAATTG-3', reverse primer, 5'- CCATCTTTGGAAGGTTCAGGTTG-3'; Cxcl1 forward primer, 5'- CGTGGCCACTGAACTGCG-3', reverse primer, 5'-TTCCGCCCATTCTTGAGTGT-3', and $\beta$-actin, 5'-CATGTACGTTGCTATCCAGGC-3'; reverse primer, 5'-CTCCTTAATGTCACGCACGAT-3'. The mean $\pm \mathrm{SD}$ of three independent experiments was shown.

\section{Chromatin immunoprecipitation (ChIP) assay}

ChIP assays were essentially performed as previously described $[57,58]$. ChIP DNA was analyzed by qPCR with SYBR Green (Bio-Rad) in ABI-7500 (Applied Biosystems) using the primers specified in the following, LGR5 forward primer: 5'AGGTCTGGTGTGTTGCTGAG-3', reverse primer: 5'- GAGTGACGTGGGGAAGTACT-3'; EGF forward primer: 5'- TCCTTTCTCTGCACTCCTGG-3', reverse primer: 5'- GTGCACATTCCAGGAGCTTT-3'; IL-6 reverse primer: 5'- CTGGAGATGTCTGAGGCTCA-3', reverse primer: 5'-CACCCCTCCCTCACACAG-3'; CXCL1 forward primer: 5' AGGCAATGTTGGAAAACGCT-3', reverse primer: 5' - TCGCCTGCAGATTGTTTAGC-3' . The antibodies used are as followed: IKK $\alpha$ (Santa Cruz), p-STAT3 (Cell Signaling, Danvers, MA), normal mouse IgG (Millipore).

\section{Nude mice and study approval}

A xenograft tumor formation was essentially performed as previously described [58]. Mice were injected with A431 $\left(2 \times 10^{6}\right.$ cells/mice $)$ and their corresponding stable clones with knockdown of LSH expression via mammary fat pad. Mice with A431 cells were imaged from dorsal and ventral views once per week. Visible lung metastatic nodules were examined macroscopically or detected in paraffin-embedded sections stained with H\&E. Data were analyzed using Student's t test; a $P$ value less than 0.05 was considered significant.

All procedures for animal study were approved by the Institutional Animal Care and Use Committee of the Central South University of Xiangya School of Medicine and conform to the legal mandates and federal guidelines for the care and maintenance of laboratory animals.

\section{Statistics}

The experiments were repeated at least three times. Results are expressed as mean $\pm \mathrm{SD}$ or SEM as indicated. A 2-tailed Student's t test was used for intergroup comparisons. A $p$ value less than 0.05 was considered statistically significant $(* p<0.05, * * p<0.01, * * * p<$ $0.001)$.

\section{ACKNOWLEDGMENTS}

We would like to thank all laboratory members for their critical discussion of this manuscript.

This work was supported by the National Basic Research Program of China [2015CB553903(Y.T.); 2011 CB504300 (Y.T.)]; the National Natural Science Foundation of China [81171881 and 81372427(Y.T.), 81271763(S.L.), 81302354(Y.S.)]; the Hunan Natural Science Foundation of China [12JJ1013(Y.T.)]; and the Fundamental Research Funds for the Central Universities [2011JQ019(Y.T.), 2013ZZTS074(B.Y.)].

\section{CONFLICTS OF INTEREST}

The authors declare no conflict of interest. This manuscript has been read and approved by all the authors, and not submitted or under consider for publication elsewhere. 


\section{Author contributions}

1) J.J., Y.S., B.Y., D.X., Y.J., Y.P., L.C., W.L., C.M., Y.C., J.Z., X.S., S.L, and Y.T. have made substantial contributions to conception and design, acquisition of data, analysis and interpretation of data; 2) Y.T. S.L. and Y.S. have been involved in drafting the manuscript critically for important intellectual content; and 3) All authors have given final approval of the version to be published.

\section{REFERENCES}

1. Barker N, van Es JH, Kuipers J, Kujala P, van den Born M, Cozijnsen M, Haegebarth A, Korving J, Begthel H, Peters PJ and Clevers H. Identification of stem cells in small intestine and colon by marker gene Lgr5. Nature. 2007; 449:1003-1007.

2. Jaks V, Barker N, Kasper M, van Es JH, Snippert HJ, Clevers $\mathrm{H}$ and Toftgard R. Lgr5 marks cycling, yet longlived, hair follicle stem cells. Nat Genet. 2008; 40:12911299.

3. Tanese K, Fukuma M, Yamada T, Mori T, Yoshikawa T, Watanabe W, Ishiko A, Amagai M, Nishikawa T and Sakamoto M. G-protein-coupled receptor GPR49 is up-regulated in basal cell carcinoma and promotes cell proliferation and tumor formation. Am J Pathol. 2008; 173:835-843

4. Hayden MS and Ghosh S. Shared principles in NF-kappaB signaling. Cell. 2008; 132:344-362.

5. Perkins ND. Integrating cell-signalling pathways with NFkappaB and IKK function. Nature reviews Molecular cell biology. 2007; 8:49-62.

6. Karin M and Greten FR. NF-kappaB: linking inflammation and immunity to cancer development and progression. Nature reviews Immunology. 2005; 5:749-759.

7. Senftleben U, Cao Y, Xiao G, Greten FR, Krahn G, Bonizzi G, Chen Y, Hu Y, Fong A, Sun SC and Karin M. Activation by IKKalpha of a second, evolutionary conserved, NFkappa B signaling pathway. Science. 2001; 293:1495-1499.

8. Vallabhapurapu S and Karin M. Regulation and function of NF-kappaB transcription factors in the immune system. Annual review of immunology. 2009; 27:693-733.

9. Sansone $\mathrm{P}$ and Bromberg J. Targeting the interleukin-6/Jak/ stat pathway in human malignancies. J Clin Oncol. 2012; 30:1005-1014.

10. Yu H, Pardoll D and Jove R. STATs in cancer inflammation and immunity: a leading role for STAT3. Nat Rev Cancer. 2009; 9:798-809.

11. $\mathrm{Yu} \mathrm{H}$, Lee $\mathrm{H}$, Herrmann A, Buettner $\mathrm{R}$ and Jove $\mathrm{R}$. Revisiting STAT3 signalling in cancer: new and unexpected biological functions. Nat Rev Cancer. 2014; 14:736-746.

12. Park EJ, Lee JH, Yu GY, He G, Ali SR, Holzer RG, Osterreicher $\mathrm{CH}$, Takahashi $\mathrm{H}$ and Karin M. Dietary and genetic obesity promote liver inflammation and tumorigenesis by enhancing IL-6 and TNF expression. Cell. 2010; 140:197-208.

13. Carro MS, Lim WK, Alvarez MJ, Bollo RJ, Zhao X, Snyder EY, Sulman EP, Anne SL, Doetsch F, Colman H, Lasorella A, Aldape K, Califano A and Iavarone A. The transcriptional network for mesenchymal transformation of brain tumours. Nature. 2010; 463:318-325.

14. Marotta LL, Almendro V, Marusyk A, Shipitsin M, Schemme J, Walker SR, Bloushtain-Qimron N, Kim JJ, Choudhury SA, Maruyama R, Wu Z, Gonen M, Mulvey LA, Bessarabova MO, Huh SJ, Silver SJ, et al. The JAK2/STAT3 signaling pathway is required for growth of CD44(+)CD24(-) stem cell-like breast cancer cells in human tumors. J Clin Invest. 2011; 121:2723-2735.

15. Schroeder A, Herrmann A, Cherryholmes G, Kowolik C, Buettner R, Pal S, Yu H, Muller-Newen G and Jove R. Loss of androgen receptor expression promotes a stem-like cell phenotype in prostate cancer through STAT3 signaling. Cancer Res. 2014; 74:1227-1237.

16. Herrmann A, Priceman SJ, Kujawski M, Xin H, Cherryholmes GA, Zhang W, Zhang C, Lahtz C, Kowolik C, Forman SJ, Kortylewski M and Yu H. CTLA4 aptamer delivers STAT3 siRNA to tumor-associated and malignant T cells. J Clin Invest. 2014; 124:2977-2987.

17. Epstein EH. Basal cell carcinomas: attack of the hedgehog. Nature reviews Cancer. 2008; 8:743-754.

18. Rogers HW, Weinstock MA, Harris AR, Hinckley MR, Feldman SR, Fleischer AB and Coldiron BM. Incidence estimate of nonmelanoma skin cancer in the United States, 2006. Archives of dermatology. 2010; 146:283-287.

19. Kasper M, Jaks V, Hohl D and Toftgard R. Basal cell carcinoma - molecular biology and potential new therapies. The Journal of clinical investigation. 2012; 122:455-463.

20. Xia X, Park E, Liu B, Willette-Brown J, Gong W, Wang J, Mitchell D, Fischer SM and Hu Y. Reduction of IKKalpha expression promotes chronic ultraviolet B exposure-induced skin inflammation and carcinogenesis. Am J Pathol. 2010; 176:2500-2508.

21. Park E, Liu B, Xia X, Zhu F, Jami WB and Hu Y. Role of IKKalpha in skin squamous cell carcinomas. Future oncology. 2011; 7:123-134.

22. Balkhi MY, Willette-Brown J, Zhu F, Chen Z, Liu S, Guttridge DC, Karin M and $\mathrm{Hu}$ Y. IKKalpha-mediated signaling circuitry regulates early B lymphopoiesis during hematopoiesis. Blood. 2012; 119:5467-5477.

23. Liu B, Willette-Brown J, Liu S, Chen X, Fischer SM and $\mathrm{Hu}$ Y. IKKalpha represses a network of inflammation and proliferation pathways and elevates c-Myc antagonists and differentiation in a dose-dependent manner in the skin. Cell death and differentiation. 2011; 18:1854-1864.

24. Xia X, Liu S, Xiao Z, Zhu F, Song NY, Zhou M, Liu B, Shen J, Nagashima K, Veenstra TD, Burkett S, Datla M, Willette-Brown J, Shen $\mathrm{H}$ and $\mathrm{Hu}$ Y. An IKKalphanucleophosmin axis utilizes inflammatory signaling to 
promote genome integrity. Cell reports. 2013; 5:1243-1255.

25. Kuo HP, Wang Z, Lee DF, Iwasaki M, Duque-Afonso J, Wong SH, Lin CH, Figueroa ME, Su J, Lemischka IR and Cleary ML. Epigenetic roles of MLL oncoproteins are dependent on NF-kappaB. Cancer cell. 2013; 24:423-437.

26. Zhang M, Liang L, Morar N, Dixon AL, Lathrop GM, Ding J, Moffatt MF, Cookson WO, Kraft P, Qureshi AA and Han J. Integrating pathway analysis and genetics of gene expression for genome-wide association study of basal cell carcinoma. Human genetics. 2012; 131:615-623.

27. Anest V, Hanson JL, Cogswell PC, Steinbrecher KA, Strahl $\mathrm{BD}$ and Baldwin AS. A nucleosomal function for IkappaB kinase-alpha in NF-kappaB-dependent gene expression. Nature. 2003; 423:659-663.

28. Yamamoto Y, Verma UN, Prajapati S, Kwak YT and Gaynor RB. Histone H3 phosphorylation by IKK-alpha is critical for cytokine-induced gene expression. Nature. 2003; 423:655-659.

29. Cao Y, Luo JL and Karin M. IkappaB kinase alpha kinase activity is required for self-renewal of ErbB2/Her2transformed mammary tumor-initiating cells. Proceedings of the National Academy of Sciences of the United States of America. 2007; 104:15852-15857.

30. Luo JL, Tan W, Ricono JM, Korchynskyi O, Zhang M, Gonias SL, Cheresh DA and Karin M. Nuclear cytokineactivated IKKalpha controls prostate cancer metastasis by repressing Maspin. Nature. 2007; 446:690-694.

31. Tan W, Zhang W, Strasner A, Grivennikov S, Cheng JQ, Hoffman RM and Karin M. Tumour-infiltrating regulatory $\mathrm{T}$ cells stimulate mammary cancer metastasis through RANKL-RANK signalling. Nature. 2011; 470:548-553.

32. Zhang W, Tan W, Wu X, Poustovoitov M, Strasner A, Li W, Borcherding N, Ghassemian M and Karin M. A NIKIKKalpha module expands ErbB2-induced tumor-initiating cells by stimulating nuclear export of p27/Kip1. Cancer cell. 2013; 23:647-659.

33. Goktuna SI, Canli O, Bollrath J, Fingerle AA, Horst D, Diamanti MA, Pallangyo C, Bennecke M, Nebelsiek T, Mankan AK, Lang R, Artis D, Hu Y, Patzelt T, Ruland $\mathrm{J}$, Kirchner $\mathrm{T}$, et al. IKKalpha promotes intestinal tumorigenesis by limiting recruitment of M1-like polarized myeloid cells. Cell reports. 2014; 7:1914-1925.

34. Liu B, Xia X, Zhu F, Park E, Carbajal S, Kiguchi K, DiGiovanni J, Fischer SM and Hu Y. IKKalpha is required to maintain skin homeostasis and prevent skin cancer. Cancer cell. 2008; 14:212-225.

35. Xiao Z, Jiang Q, Willette-Brown J, Xi S, Zhu F, Burkett S, Back T, Song NY, Datla M, Sun Z, Goldszmid R, Lin F, Cohoon T, Pike K, Wu X, Schrump DS, et al. The pivotal role of IKKalpha in the development of spontaneous lung squamous cell carcinomas. Cancer cell. 2013; 23:527-540.

36. Xiao D, Jia J, Shi Y, Fu C, Chen L, Jiang Y, Zhou L, Liu S and Tao Y. Opposed expression of IKKalpha: loss in keratinizing carcinomas and gain in non-keratinizing carcinomas. Oncotarget. 2015; 6:25499-25505. doi: 10.18632/oncotarget.4548.

37. Tam WL and Weinberg RA. The epigenetics of epithelialmesenchymal plasticity in cancer. Nature medicine. 2013; 19:1438-1449.

38. Easwaran H, Tsai HC and Baylin SB. Cancer epigenetics: tumor heterogeneity, plasticity of stem-like states, and drug resistance. Molecular cell. 2014; 54:716-727.

39. Grachtchouk M, Pero J, Yang SH, Ermilov AN, Michael LE, Wang A, Wilbert D, Patel RM, Ferris J, Diener J, Allen M, Lim S, Syu LJ, Verhaegen M and Dlugosz AA. Basal cell carcinomas in mice arise from hair follicle stem cells and multiple epithelial progenitor populations. The Journal of clinical investigation. 2011; 121:1768-1781.

40. Peterson SC, Eberl M, Vagnozzi AN, Belkadi A, Veniaminova NA, Verhaegen ME, Bichakjian CK, Ward NL, Dlugosz AA and Wong SY. Basal Cell Carcinoma Preferentially Arises from Stem Cells within Hair Follicle and Mechanosensory Niches. Cell stem cell. 2015; 16:400412.

41. Wang GY, Wang J, Mancianti ML and Epstein EH, Jr. Basal cell carcinomas arise from hair follicle stem cells in Ptch1(+/-) mice. Cancer cell. 2011; 19:114-124.

42. Hsu YC, Li L and Fuchs E. Emerging interactions between skin stem cells and their niches. Nature medicine. 2014; 20:847-856.

43. Wong SY, Seol AD, So PL, Ermilov AN, Bichakjian CK, Epstein EH, Jr., Dlugosz AA and Reiter JF. Primary cilia can both mediate and suppress Hedgehog pathwaydependent tumorigenesis. Nature medicine. 2009; 15:10551061.

44. Ning H, Mitsui H, Wang CQ, Suarez-Farinas M, Gonzalez J, Shah KR, Chen J, Coats I, Felsen D, Carucci JA and Krueger JG. Identification of anaplastic lymphoma kinase as a potential therapeutic target in Basal Cell Carcinoma. Oncotarget. 2013; 4:2237-2248. doi:10.18632/ oncotarget.1357.

45. Rao D, Macias E, Carbajal S, Kiguchi K and DiGiovanni J. Constitutive Stat3 activation alters behavior of hair follicle stem and progenitor cell populations. Molecular carcinogenesis. 2015; 54:121-133.

46. So PL, Wang GY, Wang K, Chuang M, Chiueh VC, Kenny PA and Epstein EH, Jr. PI3K-AKT signaling is a downstream effector of retinoid prevention of murine basal cell carcinogenesis. Cancer prevention research. 2014; 7:407-417.

47. Kim DJ, Angel JM, Sano S and DiGiovanni J. Constitutive activation and targeted disruption of signal transducer and activator of transcription 3 (Stat3) in mouse epidermis reveal its critical role in UVB-induced skin carcinogenesis. Oncogene. 2009; 28:950-960.

48. Grivennikov SI and Karin M. Dangerous liaisons: STAT3 and NF-kappaB collaboration and crosstalk in cancer. Cytokine \& growth factor reviews. 2010; 21:11-19. 
49. Bollrath J and Greten FR. IKK/NF-kappaB and STAT3 pathways: central signalling hubs in inflammation-mediated tumour promotion and metastasis. EMBO reports. 2009; 10:1314-1319.

50. Lee H, Herrmann A, Deng JH, Kujawski M, Niu G, Li Z, Forman S, Jove R, Pardoll DM and Yu H. Persistently activated Stat 3 maintains constitutive NF-kappaB activity in tumors. Cancer cell. 2009; 15:283-293.

51. Tamm C, Bower N and Anneren C. Regulation of mouse embryonic stem cell self-renewal by a Yes-YAP-TEAD2 signaling pathway downstream of LIF. Journal of cell science. 2011; 124:1136-1144.

52. Taniguchi $\mathrm{K}, \mathrm{Wu} \mathrm{LW}$, Grivennikov SI, de Jong PR, Lian I, Yu FX, Wang K, Ho SB, Boland BS, Chang JT, Sandborn WJ, Hardiman G, Raz E, Maehara Y, Yoshimura A, Zucman-Rossi J, et al. A gp130-Src-YAP module links inflammation to epithelial regeneration. Nature. 2015; 519:57-62.

53. Huang WC, Ju TK, Hung MC and Chen CC. Phosphorylation of CBP by IKKalpha promotes cell growth by switching the binding preference of CBP from $\mathrm{p} 53$ to NF-kappaB. Molecular cell. 2007; 26:75-87.
54. Chariot A. The NF-kappaB-independent functions of IKK subunits in immunity and cancer. Trends in cell biology. 2009; 19:404-413.

55. Hinz $M$ and Scheidereit $C$. The IkappaB kinase complex in NF-kappaB regulation and beyond. EMBO reports. 2014; 15:46-61.

56. Jiang Y, Yan B, Lai W, Shi Y, Xiao D, Jia J, Liu S, Li H, Lu J, Li Z, Chen L, Chen X, Sun L, Muegge K, Cao Y and Tao Y. Repression of Hox genes by LMP1 in nasopharyngeal carcinoma and modulation of glycolytic pathway genes by HoxC8. Oncogene. 2015; 34:6079-91.

57. Shi Y, Tao Y, Jiang Y, Xu Y, Yan B, Chen X, Xiao L and Cao Y. Nuclear epidermal growth factor receptor interacts with transcriptional intermediary factor 2 to activate cyclin D1 gene expression triggered by the oncoprotein latent membrane protein 1. Carcinogenesis. 2012; 33:1468-1478.

58. Jiang Y, Yan B, Lai W, Shi Y, Xiao D, Jia J, Liu S, Li H, Lu J, Li Z, Chen L, Chen X, Sun L, Muegge K, Cao Y and Tao Y. Repression of Hox genes by LMP1 in nasopharyngeal carcinoma and modulation of glycolytic pathway genes by HoxC8. Oncogene. 2015; 34:6079-6091. 